\title{
Monosporascus cannonballus Agente Causal do Colapso em Plantas de Melão no Rio Grande do Norte, Brasil
}

\author{
Rui Sales Jr*, Odaci F. de Oliveira, Rosemberg F. Senhor \& Maria Z. Alves \\ ${ }^{1}$ Escola Superior de Agricultura de Mossoró, Cx. Postal 137, CEP 59600-970, Mossoró, RN, e-mail: jrrui@ hotmail.com
}

(Aceito para publicação em 15/04/2003)

Autor para correspondência: Rui Sales Jr.

\begin{abstract}
Monosporascus cannonballus causal agent of collapse in melon plants in the State of Rio Grande do Norte, Brazil

A pathogenicity test has verified that Monosporascus cannonballus is, in fact, the etiological agent causing the collapse of

the melon (Cucumis melo) plant recently detected in production fields in the State of Rio Grande do Norte, Brasil. The test was carried out under controlled conditions and the infected plants showed symptoms that matched those reported previously for the disease.
\end{abstract}

A região Nordeste do Brasil apresenta uma área de aproximadamente 15.000 ha de cultivo do meloeiro (Cucumis melo L.). O cultivo intensivo e contínuo desta cucurbitácea, muitas vezes sendo em até três ciclos ao ano no mesmo solo, associado às mudanças nas práticas culturais como: introdução de cultivares híbridos, uso de cobertura plástica ("plastic mulch"), transplantio, irrigação de alta freqüência, incremento na densidade de plantação, ausência de rotações adequadas, etc. (Bruton et al., In: Cucurbitaceae '98. McCreight J., Ed., Amer. Society Hort. Sci. Press, Alex., Va. 1998 ), provocou um aumento no número e severidade das doenças radiculares. Entre estas se destacam as doenças conhecidas como "vine decline", "sudden wilt" e "colapso" ou "muerte súbita", estas sinonímias de morte súbita (Sales Jr. et al., Fitopatol. Bras. 27:206-210. 2002) que vem produzindo grandes perdas e limitando a produção deste cultivo em diversas zonas produtoras de todo o mundo.

No verão de 2002, dois campos de produção comercial de melão foram prospectados no município de Mossoró-RN. Nestes, a presença de plantas com sintomas de colapso ou declínio de ramas. Foram coletadas 100 plantas por campo e, fragmentos de raízes, com e sem a presença de frutificações fúngicas, e do colo da planta. Estes foram desinfetados em hipoclorito sódico a 1,5\% durante um minuto, seguido de dois lavados em água esterelizada no laboratório de Agricultura Irrigada da Escola Superior de Agricultura de Mossoró-ESAM. Posteriormente, foram semeados em placas de Petri (sete fragmentos por placa) com meio BDA acrescido de antibiótico e, postos para crescer em estufa a $28^{\circ} \mathrm{C}$ durante uma semana. Após a obtenção dos cultivos puros dos fungos e análise microscópica dos peritécios com ascósporos esféricos de coloração negra, medindo 25-44 mm de diâmetro (Figura 1) encontrados nas raízes, identificou-se a presença de Monosporascus cannonballus Pollack \& Uecker (Pollack \& Uecker, Mycologia 66: 348, 1974). A frequiência deste patógeno

*Bolsista do CNPq foi de $15 \%$ para ambos os campos.

O teste de patogenicidade foi realizado em condições de casa de vegetação mediante a inoculação do fungo em uma mistura de solo autoclavado com composto Plantimax ${ }^{\circledR}$ na proporção de $3: 1$. Em cada vaso com $16 \mathrm{~cm}$ de diâmetro foi adicionado, misturando-se ao substrato, um disco de meio de cultura de $70 \mathrm{~mm}$ com colônias de $M$. cannonballus com sete dias de crescimento. Sementes de melão Gold Pride da empresa Petoseed foram semeadas em número de duas por vaso, em um total de cinco vasos. Nos vasos testemunha foram adicionados apenas discos de meio de cultura. O aparecimento dos sintomas deuse a partir dos 20 dias do plantio, sendo a avaliação final do ensaio realizada aos 45 dias. O reisolamento obtido das raízes e do colo das plantas apresentou colônias com as mesmas caracterís ticas da cultura original, comprovando ser M. cannonballus o agente etiológico do colapso das plantas de melão (Marinho et al., Caatinga 15:25-28. 2002).

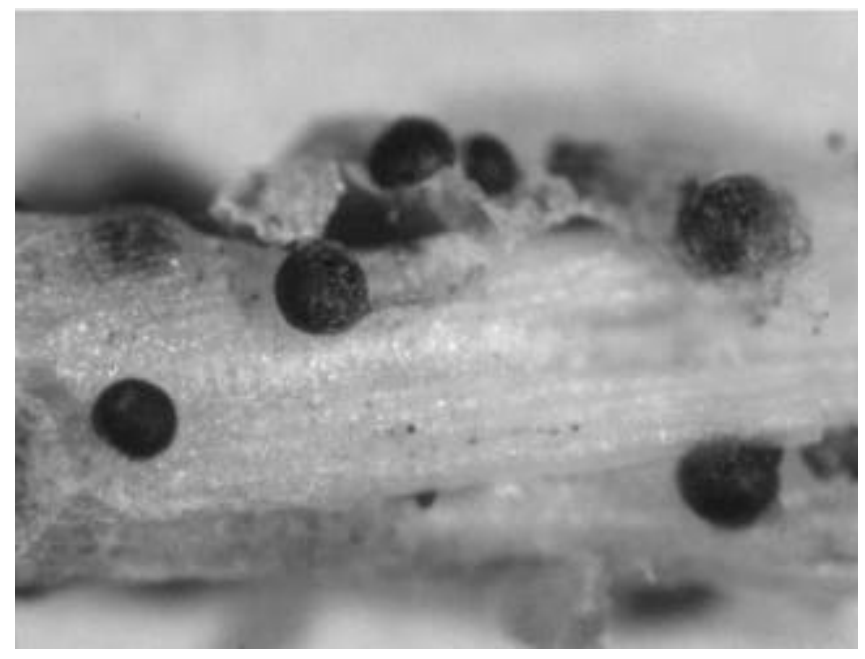

FIG. 1 - Peritécios deMonosporascus cannonballus em raízes de melão (Cucumis melo). 